fell far below the perfection to which the mnemonist aspired.

From the practical point of view, our experiments hardly provide a ready-made memory technology. There will be obvious complications if we label some real Mr Read as a librarian when he is not. We are also aware that it may be often difficult to find effective labels. By contrast with the laborious procedures of "artificial memory", however, labels facilitate recall without any special effort on the subjects' part, so it would appear worth attempting to see whether the process can be extended.

We thank the MRC for financial assistance.

$$
\text { H. C. A. DALE }
$$

Alex McGlaughlin

Department of Psychology,

University of Hull.

Received February 20, 1970

1 Yates, F. A., The Art of Memory (Penguin Books, Harmondsworth, 1969).

2 Miller, G. A., Gallanter, E., and Pribram, K. H., Plans and the Structure of Behaviour (Holt, Rinehart and Winston, New York, 1960).

\section{Memory for Syntax}

THE deep structure of a sentence, according to Chomsky ${ }^{1}$, includes ( 1 ) a specification of its fundamental grammatical relations, such as its "logical" subject and object; and (2) a series of transformational "footnotes" indicating the form taken by the actual sentence, for example, that it is passive. When a sentence is remembered verbatim, such "footnotes" seem to be separately and independently stored $^{2}$, and to take up a detectable amount of space in short-term memory ${ }^{3}$. But they may be rapidly forgotten, as Sachs ${ }^{4}$ has shown; and this is likely in ordinary discourse, because utterances are not usually remembered verbatim.

Because the grammatical relations inherent in deep structure can often be reconstructed from the meaning of the sentence, it is likely that the relations, too, are rapidly forgotten. It was therefore predicted that deop-structure relations would be forgotten if subjects were unaware that their memory was to be tested, but that they would not be forgotten if subjects expected the test. Subjects' expectations, however, would have no effect on their memory for meaning.

Two independent groups of subjects were told that their task was to make up two sentences continuing the theme of a short spoken passage. The members of the "memory" group (M) were also told that they would be given a memory test of one of the sentences in the passage; the "incidental" group (I) was given no such instruction. After listening to the tape-recorded passage, both groups were asked to select the sentence in the passage from a list of sentences presented to them. They were allowed, if necessary, to make up to four attempts.

To test the hypothesis we obviously had to use sentences whose meanings do not automatically enable the deepstructure relations to be reconstructed. The following test sentence was therefore used:

(I) John liked the painting and bought it from the duchess.

This was the fourth sentence in the spoken passage, which consisted of six sentences. The items in the recognition test also included: him.

(2) John liked the painting and the duchess sold it to

(3) The painting pleased John and he bought it from the duchess.

(4) The painting pleased John and the duchess sold it to him.
These four sentences are very similar in meaning, yet they have quite distinct deep structures; for example, John is the subject of liked, but the object of pleased. The four remaining items in the test had a different meaning and were derived by interchanging John and the duchess and altering the pronoun where appropriate (for example, "The duchess liked the painting and John sold it to her"). The eight sentences were used in six different randomized orders for the recognition test. The subjects, twenty-four students at University College, London, were assigned in rotation to a group and to one of these lists. They were tested individually.

Seven subjects out of twelve in group M. wero correct on their first selection; two subjects out of twelve in group I were correct on their first selection. This difference was significant $(P<0.05$; one-tailed, Fisher-Yates exact test) and was also reflected in the number of selections required to identify the test sentence $(P<0 \cdot 03$; one-tailed Mann-Whitney test).

Subjects were also classified into those whose choices were all semantically correct and those who made at least one semantic error. Although this was the most stringent test that could be devised, there was no reliable difference between the groups. There were no semantic errors in group $\mathbf{M}$, and only three subjects made semantic errors in group I.

The results suggest that subjects tend to retain syntax, and deep structure in particular, only if they know that they are to receive a memory test. This seemed to give riso to a difference in recall strategy. Subjects who were correct on their first attempt picked out the sentence with little hesitation, and justified their choice because it "sounded right" (or words to that effect). The other subjects took approciably longer over their choices, and justified them on more semantic grounds. It is plausible that the "memory" instructions led subjects to retain an acoustic trace of the sentence for longer than usual, perhaps by some form of rehearsal.

Although the "conclusive" bought was apparently retained better than the "non-conclusive" liked, this result may be caused by the limited nature of the materials. It could also, however, be caused by a genuine difference in the semantic complexity of conclusive and non-conclusive verbs. This sort of factor may also account for the differences in the memorability of "concrete" and "abstract" sentences ${ }^{5}$.

The most striking result, however, was that after a short time (about $50 \mathrm{~s}$ ) group I forgot the deep-structure relations of the test sentence. This result, in conjunction with Sachs's findings, suggests two alternative conclusions: (1) once the meaning of a sentence has been grasped its syntax is usually forgotten completely; or (2) Chomsky's notion of deep structure is a misleading guide to linguistic performance and should be replaced by something much closer to the meaning of the sentence ${ }^{6}$. It would then become impossible to remember meaning without remembering underlying structure.

Is syntax remembered? The answer clearly depends upon the experimenter's conception of syntax and the subject's conception of the experimental task.

We thank Dr P. C. Wason for his advice.

P. N. JoHnSON-Latrn

Department of Psychology,

Rosemary Stevenson

University College, London.

Received February 20, 1970.

${ }^{1}$ Chomsky, N., Aspects of the Theory of Syntax (MIT, Cambridge, Mass., 1965).

${ }^{2}$ Mehler, J., J. Verb. Learn. Verb. Behav., 2, 346 (1963).

${ }^{3}$ Savin, H. B., and Perchonock, E., J. Verb. Learn. Verb. Behav., 4, 348 $(1965)$.

4 Sachs, J., Percept. Psychophys, , 2, 437 (1967).

${ }^{5}$ Begg, I., and Paivio, A., J. Verb. Learn. Verb. Behav., 8, 821 (1969).

Fillmore, C. J., in Universals in Linguistic Theory (edit. by Bach, E., and Harms, R. T.) (Holt, Rinehart and Winston, New York, 1968). 